DRIGINAL PIPERS

報文直方体ガス輻射の一計算法

(24)

石谷 清 幹2) - 山䗁泰 雄3)・小泉倫吉4)

要旨：輻射ガスの黒度を指数法則にしたがうるのとして，直方体ガス体の底面端部汶対する黒度を求める方法並 びにその線図を示した。この線図を用いると，直方体ガス体風壁上の任意の点における黒度は四つの直方体ガス体の 底面端部代対する黑度の和として直ちに求めることができる。

\section{1. 緒言}

ガスおよび焰輻射関する従来の研究問題は,

（1）一百線方向の輻射に対するガス黒度の問題

（2）ガス体から全周壁への輻射に対する平均黒度の 問題

に大別される。（1）によるガスの性質の研究成果を実際 の伝熱垶置に適用寸るには（2）の研究が必要である。 (1) のガス黑度 $\varepsilon$ を $\varepsilon=1-e^{-A l}$ (但し $A$ は吸収係数 $\mathbf{m}^{-1}, l$ は軦射距離 $\mathrm{m}$ ) で表わすと，精然には実際の侣 と一致しないが大体の傾向は一致するのでありり,この 式は従来からもがス䡚射の基礎式として用いられてい る。(2) の研究のためにはにがしの単純な函数であるこ とが絶対必要であるために従来から上式による表示法が 使われているが，本論文です上の形の式を採用すること にする。立体の全周壁に対する平均照度（従つてまた相

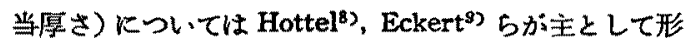
状だけを問題にして近似式を与えているが，実は形状の 他に大きさの影響るはなはた大きいことは本研究の結果 からみても明らかである。したがつて最近の大形の炬に 対しては従来の近似式の妥当性泣疑問である。これを検 討するには周壁上の各点に批る黑度を求めた上で周壁 全面に対する平均值を求めなけれ福ならない。ところが 周壁上の一点火括ける黒度を算出するための数値計算法 としては Schmidt の园式方法10〉るあるけれどる。これ ですはなはた煩㒕で突用に適しない。ところで立体の形 状を直方体に限定すると，周壁上の任意の点の黒度は線 図から直接簢単に求めるようにできるこがわかつた。 以下にその計算法についてのいる。

\section{2. 計 算 法}

Schmidt は楔形ガス体の底面微少面棈に対する黒度

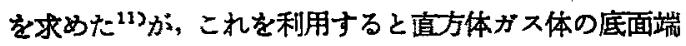

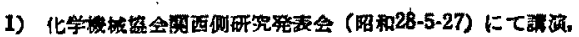
昭和 28 年 12 月 17 日原稿受理。

2) 3）大阪大学工学部

4) 目平工霜漛式会神
}

部の微少面锚に対する黒度を計算することができる。更 にこれを用いると直方体ガス体底面の任意の点济する 黑度を求めることができる。

i）楔形ガス体の底面巒少面棈 $d f$ に対する黒度

温度 $T_{g}{ }^{\circ} \mathrm{K}$ にある広い、黑体平面から温度 $T_{0}{ }^{\circ} \mathrm{K}$ の平行 黑体平面一輻射される輻射エネルギーの強さは

$$
E_{s}=C_{s}\left[\left(\frac{T_{g}}{100}\right)^{4}-\left(\frac{T_{0}}{100}\right)^{4}\right] \mathrm{Kcal} / \mathrm{m}^{2} \mathrm{~h}
$$

ただし $C_{8}$ ：黒体の輻射保数, $\mathrm{Kcal} / \mathrm{m}^{2} \mathrm{~h}\left({ }^{\circ} \mathrm{K} / 100\right)^{4}$ で示される。一方温度 $T_{g}{ }^{\circ} \mathrm{K}$ の任意の形の輻射が ス から, その内部にある温度 $T_{0}{ }^{\circ} \mathrm{K}$ の黑体表面の面䅞要素 $d f \mathrm{~m}$ ○への輻射エネルギーは次式で.ちえられる (Fig. 1 参照)。すなわち

$$
\begin{aligned}
& d w=d f \cdot \frac{E_{s}}{\Pi} \int_{\varphi=0}^{\Pi / 2} \int_{\xi=0}^{2 \Pi} \varepsilon \cdot \cos \varphi \sin \varphi d \varphi d \psi \mathrm{Kcal} / \mathrm{h} \\
& \varphi \text { : 輻射保 } \\
& \varphi \text { : 灰位角 } \\
& \varepsilon \text { ：ガスの黒度 }
\end{aligned}
$$

もしガス体が回抎体の場合には（2）式は

$$
d w=d f \cdot E_{s} \cdot 2 \int_{0}^{I / 2} \varepsilon \cos \varphi \sin \varphi d \varphi \quad \mathrm{Kcal} / \mathrm{h}(2)^{\prime}
$$

となる。ここで

$$
\varepsilon_{g}=2 \int_{0}^{\pi / 2} \varepsilon \cos \varphi \sin \varphi d \varphi
$$

をガス体の黒度と定義すると，ガス輻射の計算には結局， ガス体の黒度を計算す

ればよいことがわか る。

さて, Schmidtによ ると Fig. 2 と示すよ 5 な半径 $r$, 高さ $h$ の 円筒形均質ガス体の底 面中心㹸対する黑度 $\varepsilon_{g}$ は, $\varepsilon=1-e-A z$ か 妥当する場合には次式 で水められる。

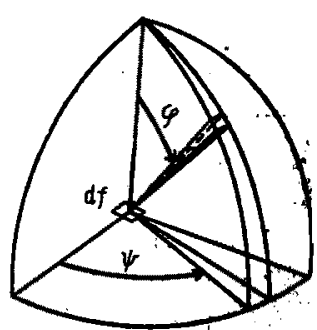

Fig. 1 


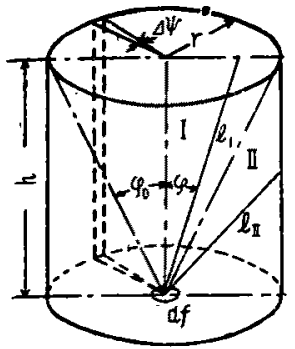

Fig. 2

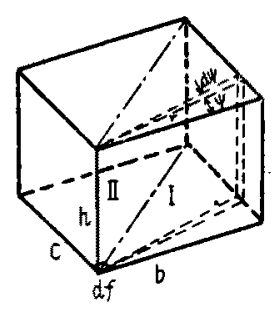

Fig. 3

$$
\begin{aligned}
& \varepsilon_{g}=\varepsilon_{g \mathrm{I}}+\varepsilon_{g \mathrm{II}} \\
& \varepsilon_{g \mathrm{I}}=2 \int_{0}^{\varphi_{0}}\left(1-e^{-A / / \cos \varphi}\right) \cos \varphi \sin \varphi d \varphi \\
& \varepsilon_{g I \mathrm{II}}=2 \int_{0}^{\varphi_{0}}\left(1-e^{-A / / \sin \varphi}\right) \cos \varphi \sin \varphi d \varphi
\end{aligned}
$$

エの樍分を行なうと次める熊度は結局

$$
\varepsilon_{g}=1-\emptyset(A h)-\theta(A r)+\emptyset\left(A V h+r^{2}\right)
$$

たたし $\omega(Z)=e^{-Z}-Z e^{-Z}-Z^{2} E_{\boldsymbol{z}}(-Z)$

$$
E_{t}(-Z)=\int_{-\infty}^{Z} \frac{e^{-x}}{x} d x
$$

となる。したがつて図示のような商さ $h$ ，半径rで锁少

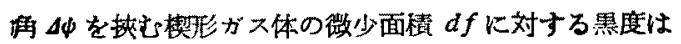

$$
\begin{array}{r}
\Delta \varepsilon_{g}=\frac{\Delta \psi}{2 \Pi}[1-\theta(A h)-\theta(A r) \\
\left.+\emptyset\left(A \sqrt{h^{2}+r^{2}}\right)\right]
\end{array}
$$

で表わされる。以上が Schmidt の理論である。

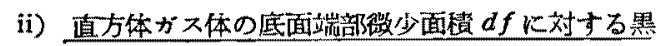
鹿

本論文では上の計算を利用して值万体底面端部の微小 面䅡 $d f$ に対するガス体黒度 $\varepsilon_{g}$ を求めることが主眼で ある。いま Fig. 3 のよ5に三边がそれぞれ $h, b, c の$ 逴方体を対何面によつて I および II の二部分に分ける

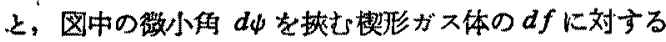
黒度は（4）式と全く同様にして

$$
\begin{aligned}
& d \varepsilon_{g \mathrm{I}}=\frac{d \phi}{2 \pi}\left[1-\theta(A h)-\theta(A r)+\theta\left(A \sqrt{h^{2}+r^{2}}\right)\right] \\
& こ こ に \quad r=\frac{b}{\cos \psi}
\end{aligned}
$$

飞なる。したがつてガス体I のdfに対する照度は

$$
\begin{aligned}
& \varepsilon_{g_{\mathrm{I}}}=\frac{1}{2 \Pi} \int_{\dot{v}_{1}}^{\psi_{2}}[1-\emptyset(A h)-\emptyset(A r) \\
& \left.+\Phi\left(A \sqrt{h^{2}+r^{2}}\right)\right] d \psi \\
& =\frac{\left(\psi_{2}-\dot{\phi}_{1}\right)}{2 \Pi}[1-\emptyset(A h)]-\frac{1}{2 \Pi} \int_{\psi_{1}}^{\phi_{2}} \emptyset\left(\frac{A b}{\cos \psi}\right) d \psi \\
& +\frac{1}{2 \pi} \int_{\phi_{1}}^{\phi_{2}} \omega\left(A \sqrt{h^{2}+\frac{b^{2}}{\cos ^{2} \phi}}\right) d \psi \text {. }
\end{aligned}
$$

たたし $\quad \phi_{1}=0 \quad \phi_{2}=\tan ^{-1} \frac{c}{b}$
で与えられる。したがつてのを多項式で表わせば上式

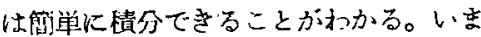

$$
\begin{aligned}
& \underset{\cos \psi}{A b} \equiv Z_{1}, \quad \emptyset\left(Z_{1}\right) \equiv K_{0}-K_{1} Z_{1}+K_{0} Z_{1}=-K_{3} Z_{1}{ }^{3} \\
& \text { 上小<之 } \\
& \int_{\psi_{1}}^{\psi_{2}} \theta\left(Z_{1}\right) d \psi=K_{n}\left(\psi_{2}-\psi_{1}\right) \\
& -K_{1} A b \times 2.3026\left\{\log \frac{\tan \left(\pi / 4+\psi_{2} / 2\right)}{\tan \left(\Pi / 4+\psi_{1} / 2\right)}\right\} \\
& +K_{2} \cdot(A b)^{n} \cdot\left\{\tan \phi_{2}-\tan \phi_{1}\right\} \\
& -K_{:} \cdot \frac{(A b)^{*}}{2}\left\{\frac{\tan \psi_{2}}{\cos \phi_{2}}-\frac{\tan \phi_{1}}{\cos \varphi_{1}}\right. \\
& \left.+2.3026 \log \frac{\tan \left(\Pi / 4+\psi_{9} / \Omega\right)}{\tan \left(\Pi / 4+\psi_{1} / \Omega\right)}\right\}
\end{aligned}
$$

また

$$
\left.\begin{array}{l}
A \sqrt{h^{2}+\frac{b^{2}}{\cos ^{2} \phi}} \equiv Z_{2} \\
\Phi\left(Z_{2}\right) \equiv K_{0}-K_{1} Z_{2}+K_{2} Z_{2}{ }^{2}-K_{8} Z_{1}^{3}
\end{array}\right\}
$$

と㕲くと

$$
\begin{aligned}
& \int_{\psi_{1}}^{\phi_{3}} \oplus\left(Z_{2}\right) d \psi=\left(\phi_{2}-\phi_{1}\right)\left\{K_{0}+K_{.}(A h)^{2}\right\} \\
& -\left\{K_{1} \cdot A b+K_{: ;} \cdot(A h)^{\mathrm{s}} \cdot k\right\} \\
& {\left[2.3026 \log \frac{t_{2}+v \sqrt{t_{2}^{2}-\left(1+k^{2}\right)}}{t_{1}+\sqrt{t_{1}^{2}-\left(1+k^{2}\right)}}\right.} \\
& \left.-\frac{1}{k}\left\{\tan ^{-1}\left(\frac{t_{2}}{\tan \psi_{2}}\right)-\tan ^{-1}\left(\frac{t_{1}}{\tan \phi_{2}}\right)\right\}\right] \\
& +K_{2}(A b)^{*}\left(\tan \psi_{2}-\tan \psi_{1}\right) \\
& -\frac{K_{3}(A h)^{3 \cdot k}}{2}\left[t_{n} k \tan \psi_{z}-t_{1} k \tan \psi_{2}\right. \\
& \left.+\left(1+k^{2}\right) \times 2.3026 \log \frac{t_{2}+\sqrt{t_{2}^{2}-\left(1+k^{2}\right)}}{t_{1}+\sqrt{\overline{t_{1}^{2}-\left(1+k^{2}\right)}}}\right]
\end{aligned}
$$

たたし

$$
\begin{aligned}
& k=\frac{A b}{A h}, t=\sqrt{1+\frac{k^{2}}{\cos ^{2} \phi}} \\
& \sqrt{t^{2}-\left(1+k^{2}\right)}=k \tan \psi
\end{aligned}
$$

となる。

次に，ガス体 II $の d f$ に対する黑度 $\varepsilon_{g I I}$ b $\varepsilon_{g I}$ と全 く同様にて求められる。すなわち

$$
\begin{gathered}
\varepsilon_{g_{11}}=\frac{1}{2 \pi} \int_{\varphi_{1}}^{\varphi_{2}}[1-\varphi(A h)-\varphi(A r) \\
\left.+\varphi\left(A \sqrt{h^{2}+r^{2}}\right)\right] d \varphi \\
=\frac{\left(\varphi_{2}-\varphi_{1}\right)}{2 \Pi}[1-\varphi(A h)]-\frac{1}{2 \pi} \int_{\varphi_{1}}^{\varphi_{2}} \varphi\left(\frac{A c}{\cos \varphi}\right) d \varphi \\
+\frac{1}{2 \pi} \int_{\varphi_{1}}^{\varphi_{9}} \emptyset\left(A \sqrt{h^{2}+\frac{c^{2}}{\cos ^{2} \varphi}}\right) d \varphi \quad(10) \\
\varphi_{1}=0 \quad \varphi_{2}=\tan ^{-1} \frac{b}{c}
\end{gathered}
$$

となるから 


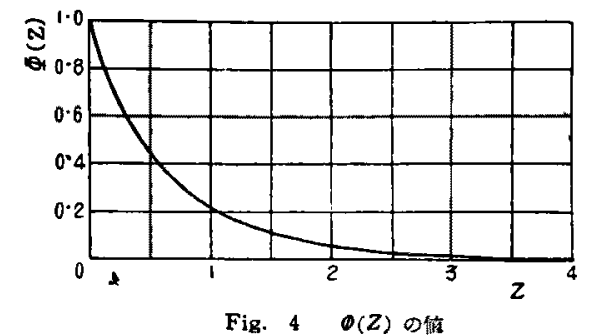

Fig. $40(Z)$ ○位
(4) $1.5<Z<3.5$;

$\emptyset(Z)=0.4972-0.4061 Z+0.1179 Z^{2}-0.0119 Z^{2}$

(5) $3.5<Z<5.5$;

$\emptyset(Z)=0.16915-0.09358 Z+0.01773 Z^{2}$

$-0.0011415 z^{3}$

上の近似式から求めた $の(Z)$ の值と真の值とを比較し て示すと Table 1 のようになる。

の(Z) を近似したために生するる䜠差は
Table $1 \quad \theta(Z)$ の值

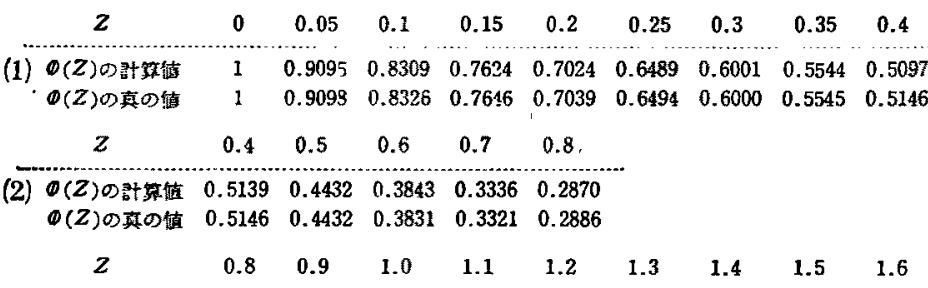

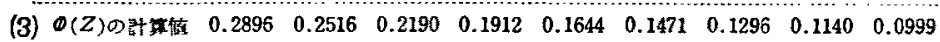
$\begin{array}{llllllllll}\theta(Z) \oplus \text { 葢O榙 } & 0.2886 & 0.2516 & 0.2194 & 0.1917 & 0.1680 & 0.1468 & 0.1296 & 0.1142 & 0.1011\end{array}$

$Z$

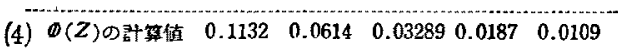

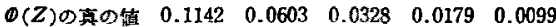

$\boldsymbol{Z}$

3.54 .0

4.

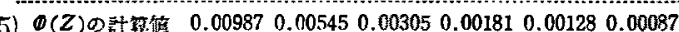

$\emptyset(Z) の$ 卖の萑 $\quad 0.009850 .005450 .00308 \quad 0.001750 .001320 .001$
Table $2 \quad O(Z)$ の值

\begin{tabular}{|c|c|c|c|c|c|c|c|c|c|}
\hline$Z$ & 6 & 7 & 8 & 9 & 10 & 11 & 12 & 14 & 15 \\
\hline$D(Z)$ & .000568 & .0001881 & .0000624 & .00000214 & .000007 & .0000024 & .0000013 & .0000005 & .0000001 \\
\hline
\end{tabular}

$$
\begin{aligned}
& \frac{1}{2 \pi} \int\{-\varphi(A r) \\
& \left.\quad+\oplus\left(A \sqrt{h^{2}+r^{2}}\right)\right\} d \psi
\end{aligned}
$$

の皘分項に基つく。この棈分の 全棈分領域は $\Pi / 2$ である。い ま $\emptyset(Z)$ が全領㳦で 0.005 の誤 差を合むとすると，最悪の場合 $1 / 4 \times 0.01=0.0025$ の誤差を 生じることになる。しかし実祭 上それ程大きな誤差か現われる ことは考穴られず小数点以下三 标究では十分正確とみなし る。

$Z$ が5.5 以上のときは積分は 省略しての(Z) の值に角度を接 けて棈分值にかえる。この場合 の $(()$ の値杜 Table 2 к示 す通りである。

上に示したの(Z)の近似式を 用いると $\varepsilon_{g}$ は結局次式から求 めることができる。

$$
\begin{aligned}
\varepsilon_{g} & =\varepsilon_{g_{1}}+\varepsilon_{g_{2}} \\
& =\frac{1}{4}[1-\emptyset(A h)]
\end{aligned}
$$

$$
\mathrm{Z}_{1}=\frac{A c}{\cos \phi}, \mathrm{Z}_{2}=A \sqrt{\frac{c^{2}+\frac{c^{2}}{\cos ^{2}-\varphi}}{2}}
$$

と拈けば $\varepsilon_{g \mathrm{I}}$ と同し式から求めることができる。

以上から $\oplus(Z)$ を $Z$ の三次式て近似することができ

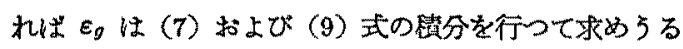
ことがわかつた。ところでけ(Z) はFig. 4 に示すよう な曲線になるか，適当な区間に分けると次式を用いて近 似できる。

$$
\text { (1) } \begin{aligned}
& 0<Z<0.4 ; \\
& \oplus(Z)=1-1.942 Z+2.749 Z^{3}-2.395 Z^{3} \\
& \text { (2) } 0.4<Z<0.8 ; \\
&(Z)=0.994-1.723 Z+1.565 Z^{2}-0.645 Z^{3} \\
& \text { (3) } 0.8<Z<1.6 ; \\
& \emptyset(Z)=0.873-1.121 Z+0.581 Z^{2}-0.114 Z^{3}
\end{aligned}
$$

$$
\begin{aligned}
& +\frac{1}{2 I}\left[\int_{0}^{\tan -1(c / b)} \oplus\left(A j^{\prime} \frac{h^{2}+\frac{b^{2}}{\cos ^{2} \psi}}{h^{2}}\right) d \psi\right. \\
& +\int_{0}^{\tan -1(b / c)} \oplus\left(A \sqrt{h^{2}+\frac{c^{2}}{\cos ^{2} \psi}}\right) d \psi \\
& \left.-\int_{0}^{\tan ^{-1}(c / b)} \oplus\left(\frac{A b}{\cos \psi}\right) d \psi-\int_{0}^{\tan -1(b / c)} \cdot\left(\frac{A c}{\cos \psi}\right) d \psi\right]
\end{aligned}
$$

この算式を用いて $A b: A c$ がそれそれ $(1: 1)(2: 1)$ $(3: 1)(4: 1)(5: 1)(6: 1)(8: 1)(10: 1)(12: 1)$ (20:1) の各場合炕つて $A b$ と $A h$ を变えて $\varepsilon_{g}$ を求

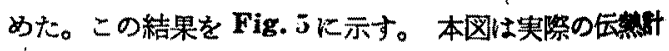
算において計算图表として利用することができる。

iii）直方体ガス体の底面の任意の点に対寸る黒度の 求め方 


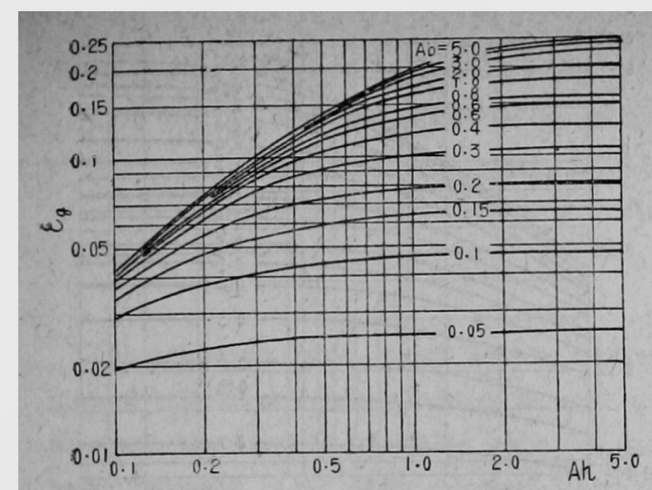

(a) $A b: A c=1: 1$

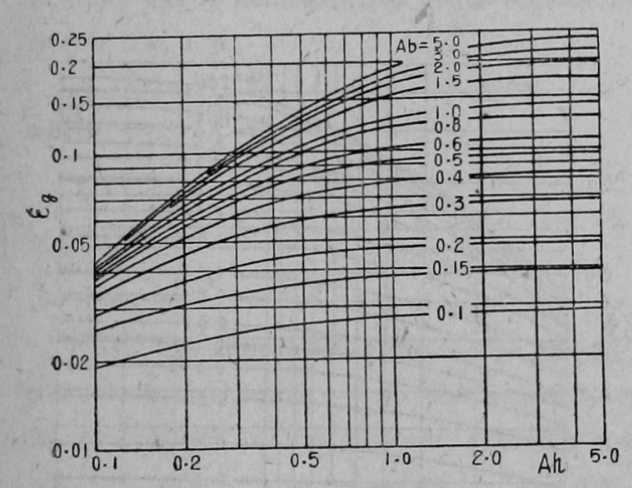

(c) $A b: A c=3: 1$

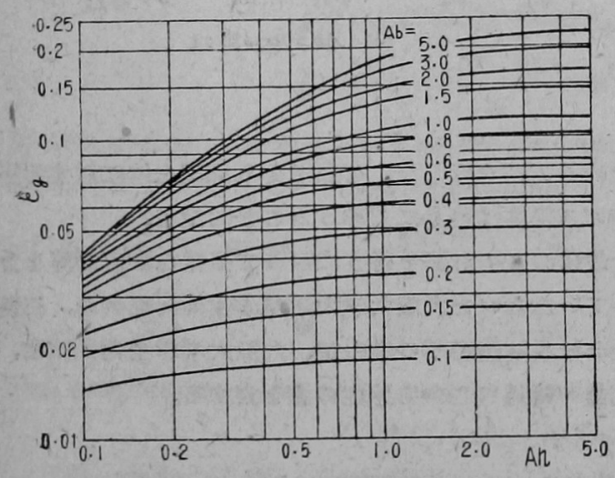

(e) $A b: A c=5: 1$

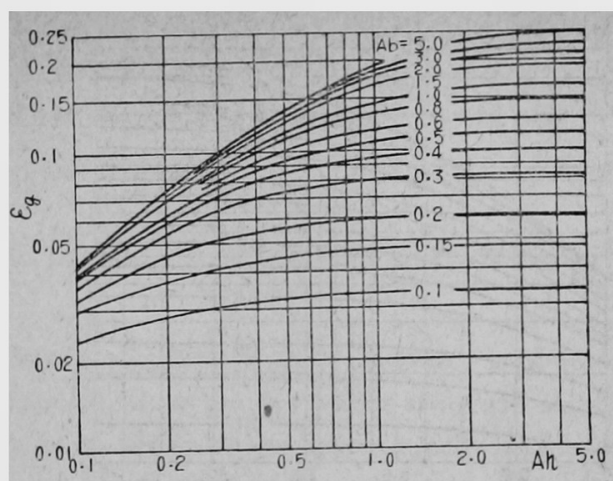

(b) $A b: A c=2: 1$

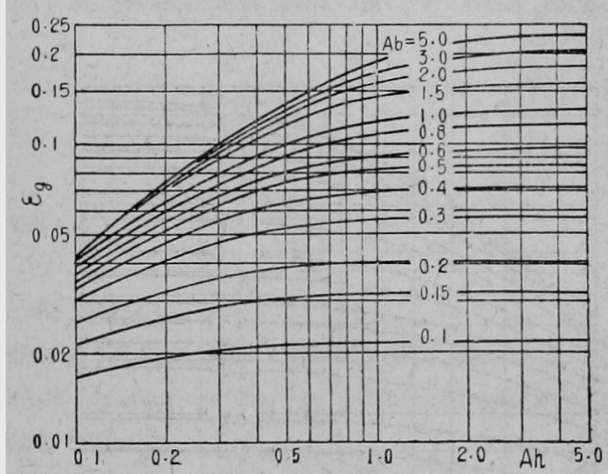

(d) $A b: A c=4: 1$

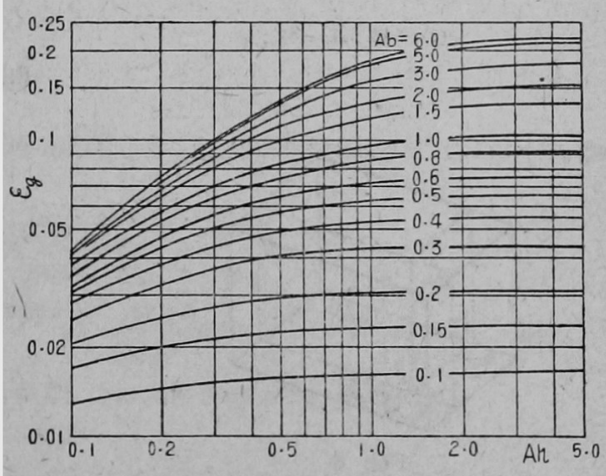

(f) $A b: A c=6: 1$

Fig. 5

Fig. 6 に示すような直方体底面の任意の一点 $P$ に対 する黒度は, 四つの直方体 I, II, III および IV の $P$ 点に対する黒度の和として与えられる。したがつて上に 求めた線図を利用すると任意の点 $P$ に対する黑度は直 ちに求められる。Fig. 万では $A h$ は 0.1 から 5 までの

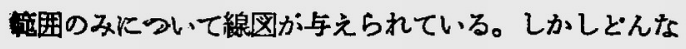

寸法㕩合でどんな大きさの直方体の場合でも $\varepsilon_{g}$ は $A h$ $=5$ でほぼ最大値に達することは線図から明らかであ る。したがつて $A h$ か 5 以上の範囲では $A h=5$ に相些 する $\varepsilon_{g}$ の值を用いればよい。また $A h$ が 0.1 より小さ いところについては，同線図を普通目盛の線図にひき㨁 し $A h=0$ で $\varepsilon_{g}=0$ となるこ上を利用すれば $\varepsilon_{g}$ を線図 


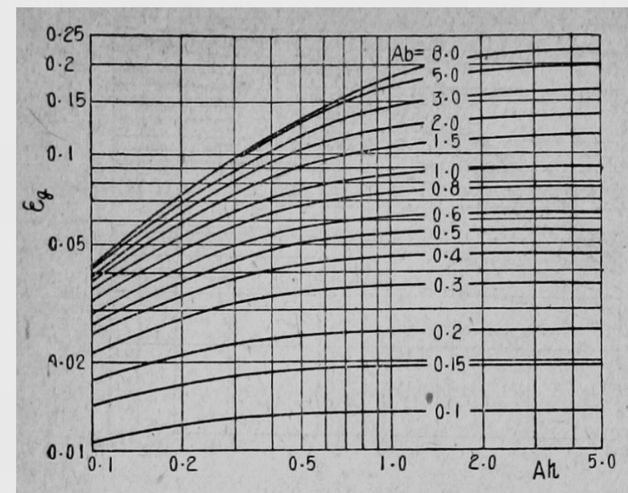

(g) $A b: A c=8: 1$

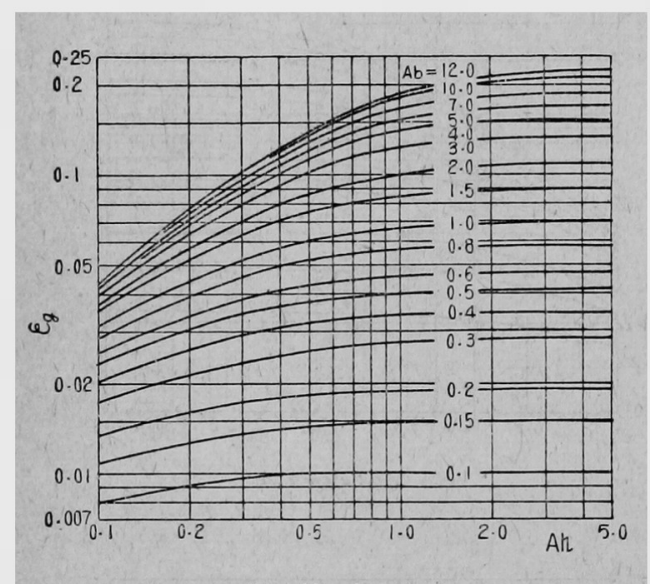

(i) $A b: A c=12: 1$

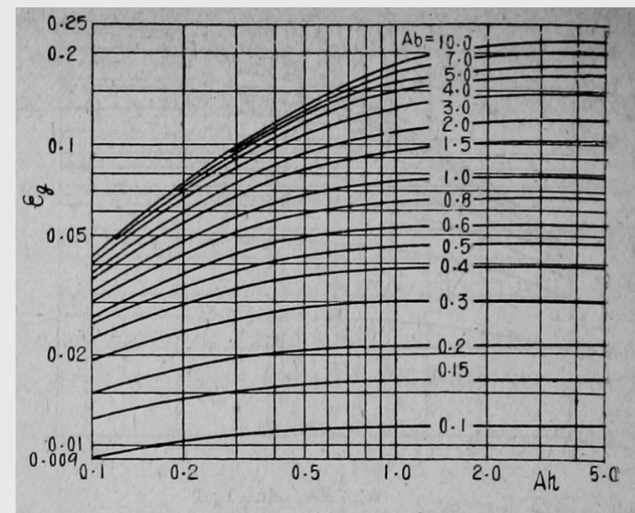

(h) $A b: A c=10: 1$

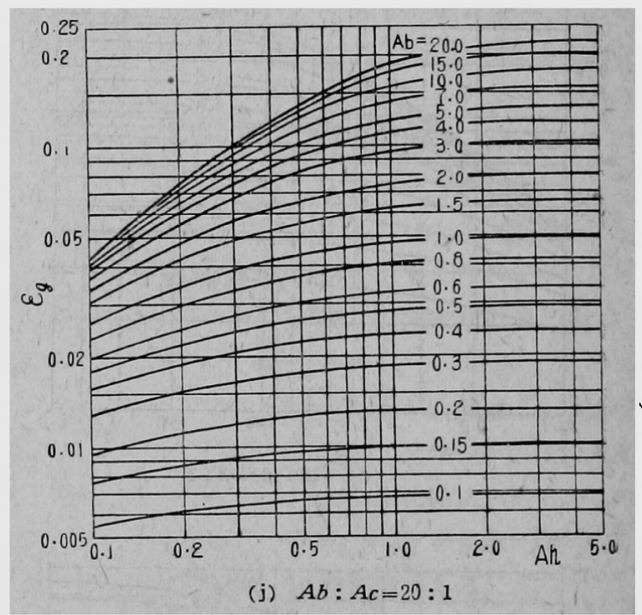

Fig. 5

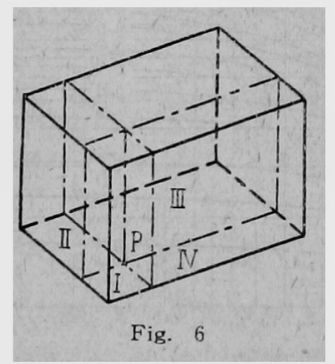

求める方法を示した。これにより周壁全体に対する平均 のガス黒度は容易に求め5ることになる。

最後汇匹の計算を行 5 亿当って煩雑な数值計算を分担 していただいた大阪大学大学院学生の阿部久郎, 三菱造 船会社長崎造船所の串山正, 大阪大学学生角井誠治, 近 江昌の諸氏に心から感謝の意を表する。

註

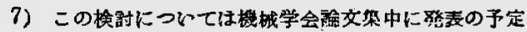

8) 例元は McAdams "Heat Transmission" 2nd ed. (1942)

9) VDI-Forschungsheft, 387 (1937)

10) Z. VDI. Bd 77 Nr. 43 S. 1162

11) 10)に同じ。

\section{3. 結語'}

以上直方体㮶壁上の任意の一点に対するガス体黒度を 


\title{
Calculation of Gas Radiation from Rectangular Parallelepiped Gas Masses
}

\author{
S. Ishigai, Y. Yamasaki \& R. Koizumi
}

The equivalent beam length for the radiation from gas masses to their boundary surfaces 29 given by Hottel and Eckert results in good approximation when the gas bodies are small in size. However, the error is inevitable when the gas body is as large as some furnaces including modern boiler furnaces. An exact calculation was practically impossible because the calculation was so tedious. In this paper is presented a simple method of calculation under the usual assumptions that the gas is homogeneous in its temperature and composition and that the radiation follows Beer's law, i. e.,

$$
\varepsilon_{g}=1-e-A l
$$

where

$$
\begin{aligned}
\varepsilon_{g} & =\text { gas emissivity, } \\
A & =\text { coefficient of absorption, } \\
l & =\text { path length, } \\
e & =\text { base of hyperbolic logarithms. }
\end{aligned}
$$

Then, the emissivity of the wedge-shaped gas mass, as shown in Fig. 2 , with height $h$ and cross section $1 / 2 r^{2} \Delta \psi$ - an element of a cylindrical volume - to the infinitesimal area $d f$ can be obtained by the following equation given by E. Schmidt:

$$
\Delta \varepsilon_{g}=\frac{\Delta \psi}{9 \Pi}\left[1-\emptyset(A h)-\emptyset(A r)+\emptyset\left(A \sqrt{h^{2}+r^{2}}\right)\right]
$$

where

$$
\begin{aligned}
& \quad(Z)=e^{-Z}-Z e^{-Z-Z} E_{i}(-Z) \\
& \quad E_{i}(-Z)=\int_{-\infty}^{Z} \frac{e^{-x}}{x} d x
\end{aligned}
$$

By integration, the emissivity at the corners of the surface $b c$ in the rectangular parallelepiped $b \times c \times h$ is given by the following equation :

$$
\begin{aligned}
\varepsilon_{g}= & \frac{1}{4}[1-\emptyset(A h)]-\frac{1}{2 \Pi}\left[\int_{0}^{\tan -1(b / c)} \oplus\left(A \sqrt{h^{2}+\frac{b^{2}}{\cos ^{2} \psi}}\right) d \psi\right. \\
& \left.+\int_{0}^{\tan -1(c / b)} \oplus\left(A \sqrt{h^{2}+\frac{c^{2}}{\cos ^{2} \psi}}\right) d \psi-\int_{0}^{\tan -1(b / c)} \oplus\left(\frac{A b}{\cos \psi}\right) d \psi-\int_{0}^{\tan -1(c / b)} \oplus\left(\frac{A c}{\cos \phi}\right) d \psi\right]
\end{aligned}
$$

The integration can be performed by transforming $\Phi(Z)$ into the following equation :

$$
\varphi(Z)=K_{0}-K_{1} Z+K_{1} Z^{2}-K_{3} Z^{3}
$$

The results of the integration are summarized in Fig. 5 for various shapes and sizes of rectangular parallelepipeds. To find the emissivity at any point on the base surface of any rectangular parallelepiped, divide the parallelepiped into four parallelepipeds by two planes passing through the point. Then the emissivity for the four parallelepipeds to the point can readily be obtained from Fig. 5. The sum of the four emissivities is the emissivity in question. 